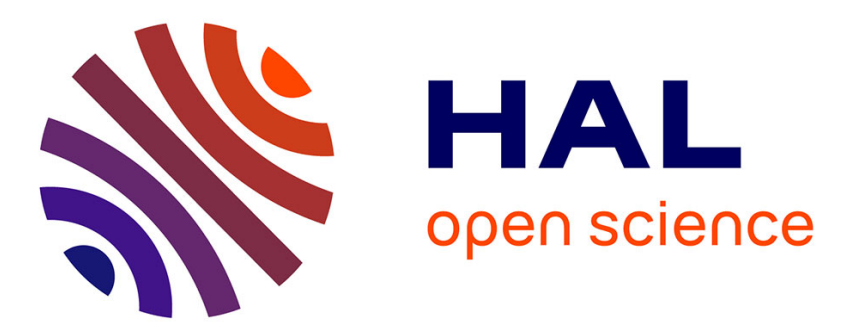

\title{
Axillary web syndrome after axillary dissection in breast cancer: a prospective study
}

María Torres Lacomba, Orlando Mayoral del Moral, José Luís Coperias Zazo, María José Yuste Sánchez, Jean-Claude Ferrandez, Álvaro Zapico Goñi

\section{- To cite this version:}

María Torres Lacomba, Orlando Mayoral del Moral, José Luís Coperias Zazo, María José Yuste Sánchez, Jean-Claude Ferrandez, et al.. Axillary web syndrome after axillary dissection in breast cancer: a prospective study. Breast Cancer Research and Treatment, 2009, 117 (3), pp.625-630. 10.1007/s10549-009-0371-8 . hal-00535349

\section{HAL Id: hal-00535349 https://hal.science/hal-00535349}

Submitted on 11 Nov 2010

HAL is a multi-disciplinary open access archive for the deposit and dissemination of scientific research documents, whether they are published or not. The documents may come from teaching and research institutions in France or abroad, or from public or private research centers.
L'archive ouverte pluridisciplinaire HAL, est destinée au dépôt et à la diffusion de documents scientifiques de niveau recherche, publiés ou non, émanant des établissements d'enseignement et de recherche français ou étrangers, des laboratoires publics ou privés. 


\title{
Axillary web syndrome after axillary dissection in breast cancer: a prospective study
}

\author{
María Torres Lacomba · Orlando Mayoral del Moral · \\ José Luís Coperias Zazo • María José Yuste Sánchez • \\ Jean-Claude Ferrandez · Álvaro Zapico Goñi
}

Received: 1 December 2008/Accepted: 5 March 2009/Published online: 21 March 2009

(C) Springer Science+Business Media, LLC. 2009

\begin{abstract}
The axillary web syndrome is a self-limiting and frequently overlooked cause of significant morbidity in the early post-operative period after breast cancer axillary surgery, which is characterized by axillary pain that runs down the medial arm, limited shoulder range of motion affecting mainly shoulder abduction, and cords of subcutaneous tissue extending from axilla into the medial arm, made visible or palpable and painful by shoulder abduction. We evaluated the incidence of axillary web syndrome after axillary lymph-node dissection. Altogether 116 patients who underwent axillary lymph-node dissection were assessed for axillary web syndrome. Range of shoulder abduction, pain, and the subjective feeling of
\end{abstract}

M. Torres Lacomba · M. J. Yuste Sánchez

Alcalá de Henares University, Madrid, Spain

M. Torres Lacomba · M. J. Yuste Sánchez

Physical Therapy Research Department, Department of Physical

Therapy, Alcalá University, Madrid, Spain

O. Mayoral del Moral

Provincial Hospital, Toledo, Spain

J. L. Coperias Zazo

Del Henares Hospital, Madrid, Spain

J.-C. Ferrandez

Lymphology Consultation, Sainte Catherine Institut,

Avignon, France

Á. Zapico Goñi

Príncipe de Asturias University Hospital, Madrid, Spain

M. Torres Lacomba ( $\square)$

E.U.E. Fisioterapia, Universidad de Alcalá, Campus Externo

Ctra. Madrid-Barcelona Km. 33.600, 28071 Alcalá de

Henares Madrid, Spain

e-mail: maria.torres@uah.es tightness along the arm were recorded. Axillary web syndrome was found in 56 patients, which means an incidence of $48.3 \%$ (CI95\%: $38.9,57.7$ ). Axillary web syndrome is a significant self-limited cause of morbidity of axillary surgery ocurring not only in the early post-operative period.

Keywords Axillary web syndrome - Incidence · Breast cancer - Axillary lymph-node dissection . Pain

\section{Introduction}

The axillary surgery, either by axillary lymph-node dissection (ALND) or by sentinel lymph-node dissection is an important procedure in the surgical treatment of breast cancer, allowing a prognostic purpose, reducing recurrence and contributing to plan an appropriate adjuvant therapy program [1-5]. Axillary surgery also has post-operative morbidity including early and long term complications as bleeding, infection at the operation site, axillary web syndrome (AWS), arm or shoulder weakness and motion restriction, swelling, numbness, pain and lymphedema [6-14].

The AWS is a self-limited and frequently overlooked cause of significant morbidity in the early post-operative period after axillary surgery. The term AWS was coined by Moskovitz et al. [15], although it was first described by Ferrandez and Serin in 1996 under the name of superficial lymphatic thrombosis [16]. The pathogenesis proposed by both research groups is lymphovenus damage, hypercoagulation, superficial venous and lymphatic stasis as well as disorders and injuries of tissues as a result of the disruption of superficial lymphatics and vessels during axillary surgery $[15,16]$. Ferrandez and Serin are even more specific 
as to the origin of the problem, and they attribute it to the hypercoagulation and inflammation of the lymphatic vessel as a result of the ALND [16]. Subsequent studies have corroborated the proposed pathogenesis [17-20]. The AWS is characterized by axillary pain that runs down the medial arm reaching the elbow, and including, in some cases, the ulnar side of forearm, wrist and hand; limited range of motion (ROM) of the shoulder, mainly for abduction; and cords of tissue (like guitar strings) extending from axilla into medial arm, made visible or palpable and painful by shoulder abduction (Fig. 1). So far, this syndrome has been poorly studied, since there are only two published incidence studies, with very different outcomes [15, 18], and four case reports [19, 21-23]. Two of these case reports propose a mode of therapy [21, 22]. The aim of this study was to objectively determine the incidence of AWS after ALND.

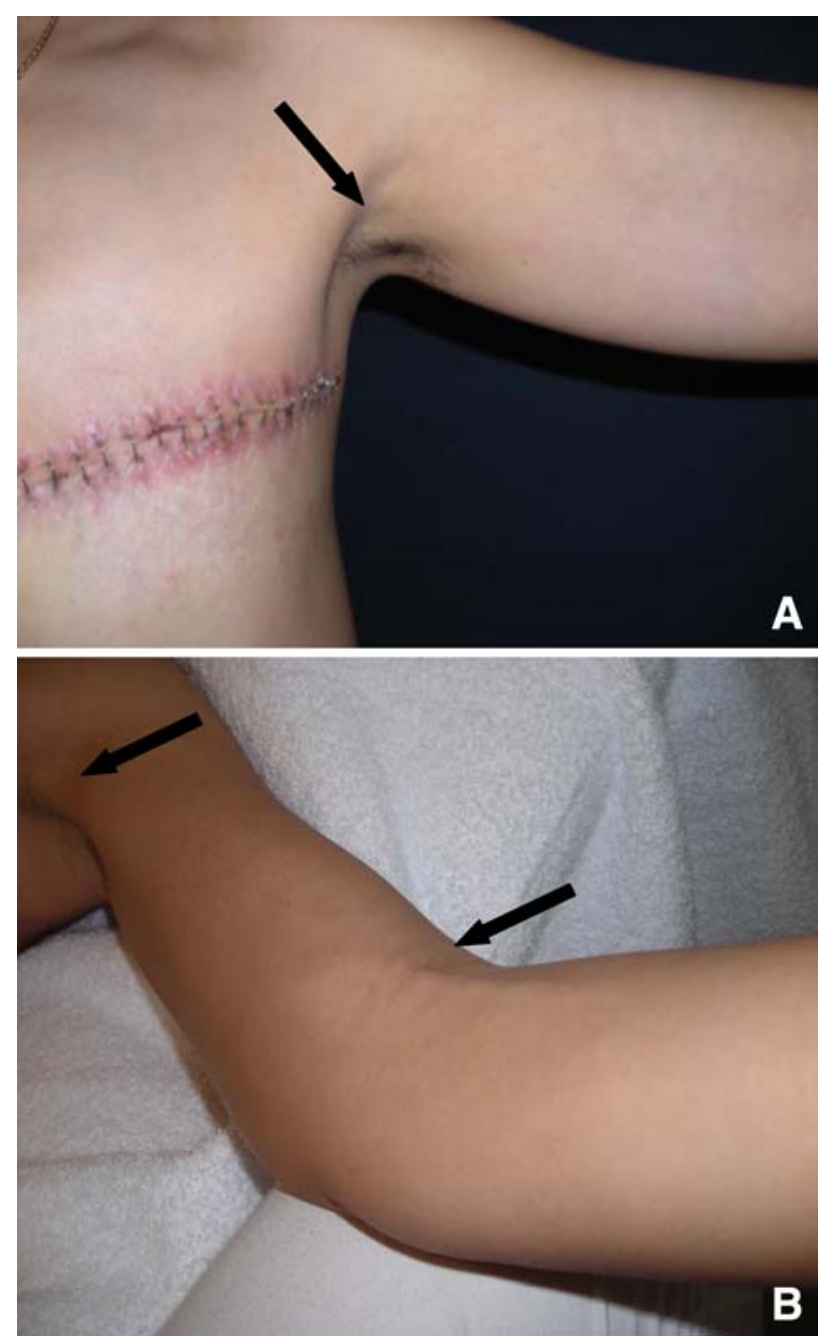

Fig. 1 a Patient demonstrating axillary web syndrome in left arm with taut cords in the axilla. b Patient demonstrating axillary web syndrome in left arm with taut cords extending from the axilla to the elbow

\section{Patients and methods}

Consecutive women diagnosed with breast cancer between May 2005 and June 2007, and undergoing unilateral surgery with ALND at the Príncipe de Asturias Hospital in Alcalá de Henares, Madrid (Spain), were candidates for inclusion in the study. Patients without ALND were excluded from the study. After biopsy confirmation of breast carcinoma, patients under the care of any one of four breast surgeons participating in the study were approached by the investigators for inclusion in the study. One hundred and twenty women out of 270 women who met the inclusion criteria agreed to participate, giving their writteninformed consent. Progress of subjects through the phases of the study is shown in Fig. 2.

\section{Assessments}

Each participant was assessed preoperatively, and then post-operatively, on hospital discharge (between Day 3 and 5), 4 weeks, and 3, 6 and 12 months after surgery. In addition to these scheduled examinations, each patient were told to inform to research team in case they experienced pain, and were assessed at that time.

This observational study was conducted as a prospective and longitudinal study. A physical therapist performed follow-up assessments.

During the preoperative assessment, demographic data were collected on all patients including age, race, marital status, body mass index (BMI) $[\mathrm{BMI}<25=$ normal

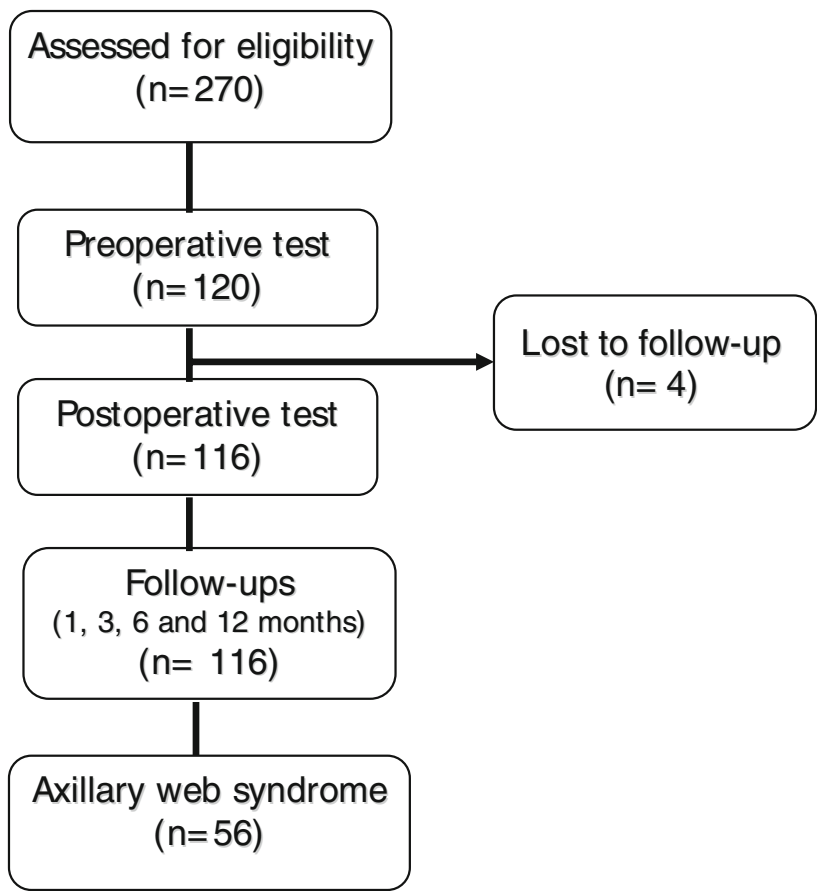

Fig. 2 Patient flow chart 
weight; $\mathrm{BMI} \geq 25=$ overweight; $\mathrm{BMI}$ of 30 or greater $=$ obesity], job, educational level, socioeconomic status, information regarding breast cancer, and medical history. They were also asked an open question about whether they felt any pain.

In post-operative assessments, data were collected regarding the type of the surgery performed, the number of lymph nodes removed, and the development of seroma, infection as well as the presence of subjective feeling of tightness (SFT), limitation of shoulder abduction, and pain in ipsilateral arm. If there was pain, the patient was again examined to determine the cause, including assessment of AWS. Pain descriptions by the patients and pain pattern drawings in body forms guided the physical examination, to determine the cause of pain. The extent of AWS was evaluated by patient ${ }^{\prime} \mathrm{s}$ pain description and by inspection and palpation of the axilla and the arm. The ROM of shoulder abduction was measured using a digital goniometer (Guymon, Model 01129, Lafayette, USA) with certificate of calibration so the stability of the measurements along the process was guaranteed. The pain intensity was registered by visual analog scale (VAS). The VAS is quick, reliable, and valid for measuring pain and pain relief $[24,25]$. The reasons for limited movements and for pain were registered.

The diagnostic criteria for AWS were pain and restriction of shoulder ROM, with associated visible or palpable taut cords of tissue in the axilla in maximal shoulder abduction. Absence of erythema, warmth or any other inflammatory sign ruled out superficial thrombophlebitis in all of our patients. Palpable taut cords (like guitar strings) were found in all patients diagnosed of AWS in our sample.

Study design

We conducted a prospective and longitudinal study. Príncipe de Asturias Hospital's Human Research Ethics Committee approved the study.

\section{Procedure}

One hundred and twenty patients were assessed for AWS diagnose. Immediately after hospital discharge, patients were taken to the AWS incidence assessment.

\section{Data analysis}

Sample-size calculations

In order to evaluate the incidence of AWS after ALND we recruited 120 women. Sample-size estimation was done assuming an incidence of AWS of $50 \%$ in the control group, according to findings in previous studies [15, 18].
With such a sample-size, and after 3\% of drop-outs (four women), we can detect an incidence difference of $20 \%$ with a precision of $13 \%$ at $95 \%$ confidence level.

Statistical analysis

Statistical analyzes were performed using Statistical Package for the Social Sciences software (12.0 version, SPSS Inc. Chicago, USA) [26]. Data were collected in a questionnaire form and introduced in an ACCESS database. These analyzes included the 116 subjects with ALND that completed baseline and all the programmed follow-up assessments.

We used the one-sample Kolmogorov-Smirnov test to assess the normal distribution, the non-parametric $\chi^{2}$ test and Mann-Whitney test or parametric $t$-test to analyze the association of the categorical and continuous variables.

The sample-size and the incidence were estimated with the !NP !NPD, and !CIP macros [27, 28].

\section{Results}

One hundred and sixteen women completed all the followup assessments, four were excluded because they did not attend the first post-surgery assessment and were lost to follow-up.

For a descriptive summary of the variables in the whole sample see Table 1.

\section{Incidence}

Axillary web syndrome was found in 56 patients meaning an incidence of $48.3 \%$ (CI95\%: 38.9, 57.7). The mean pain intensity measured by VAS was $7.7 \pm 1.1$, the average ROM of shoulder abduction was $88^{\circ} \pm 15^{\circ}$ and all felt SFT.

The incidence of AWS was influenced by BMI $(P$-value $=0.0001)$.

Axillary web syndrome developed mainly during the 2 week period after surgery. The onset of AWS, expressed as median (25th percentil-75th percentil) was 16 (12-22) days (Fig. 3).

Three months after surgery, full range of shoulder abduction and no pain compared with the post-operative measurement for AWS diagnosis was found in all patients except two. Two patients had residual signs of AWS remaining 3 months after surgery.

\section{Discussion}

The main finding of this prospective study was the incidence of AWS after ALND. The findings of the two 
Table 1 Characteristics of the 116 breast cancer patients who underwent ALND
$P^{*} P$-values from $\chi^{2}$ test $P^{* *} P$-values from $t$-test and Mann-Whitney test

\begin{tabular}{|c|c|c|c|c|c|c|c|}
\hline \multirow[t]{2}{*}{ Valid individuals } & \multicolumn{2}{|c|}{ All sample } & \multicolumn{2}{|l|}{ AWS } & \multicolumn{2}{|c|}{ No AWS } & \multirow[t]{2}{*}{$P^{*}$} \\
\hline & 116 & $100 \%$ & 56 & $100 \%$ & 60 & $100 \%$ & \\
\hline \multicolumn{8}{|l|}{ Categorical variables } \\
\hline Surgical procedure & & & & & & & 0.203 \\
\hline Quadrantectomy & 47 & 41 & 24 & 43 & 23 & 38 & \\
\hline Modified Mastectomy & 42 & 36 & 16 & 29 & 26 & 43 & \\
\hline Lumpectomy & 27 & 23 & 16 & 29 & 11 & 18 & \\
\hline Radiotherapy & 93 & 80 & 50 & 89 & 43 & 72 & 0.021 \\
\hline Chemotherapy & 95 & 82 & 52 & 93 & 43 & 72 & 0.004 \\
\hline Hormonotherapy & 72 & 62 & 36 & 64 & 36 & 60 & 0.703 \\
\hline Myofascial pain syndrome & 52 & 45 & 31 & 55 & 21 & 35 & 0.040 \\
\hline Seroma & 33 & 28 & 14 & 25 & 19 & 32 & 0.537 \\
\hline Wound infection & 11 & 9 & 5 & 9 & 6 & 10 & 0.703 \\
\hline \multirow[t]{2}{*}{ Working } & 47 & 41 & 30 & 54 & 17 & 28 & 0.008 \\
\hline & Mean & SD & Mean & SD & Mean & SD & $P^{* *}$ \\
\hline \multicolumn{8}{|l|}{ Numerical variables } \\
\hline No of dissected lymph nodes & 13.6 & $(5.2)$ & 12.9 & $(4.4)$ & 14.3 & 6.0 & 0.130 \\
\hline Age (years) & 52.9 & $(10.8)$ & 48.9 & $(10.2)$ & 58.1 & 10.9 & $<0.0001$ \\
\hline Body mass index (BMI) & 27.9 & $(5.6)$ & 25.1 & $(4.8)$ & 28.9 & 4.8 & $<0.0001$ \\
\hline Days of drainage & 4.4 & $(2.2)$ & 4.0 & (1.6) & 4.7 & 2.6 & 0.083 \\
\hline
\end{tabular}

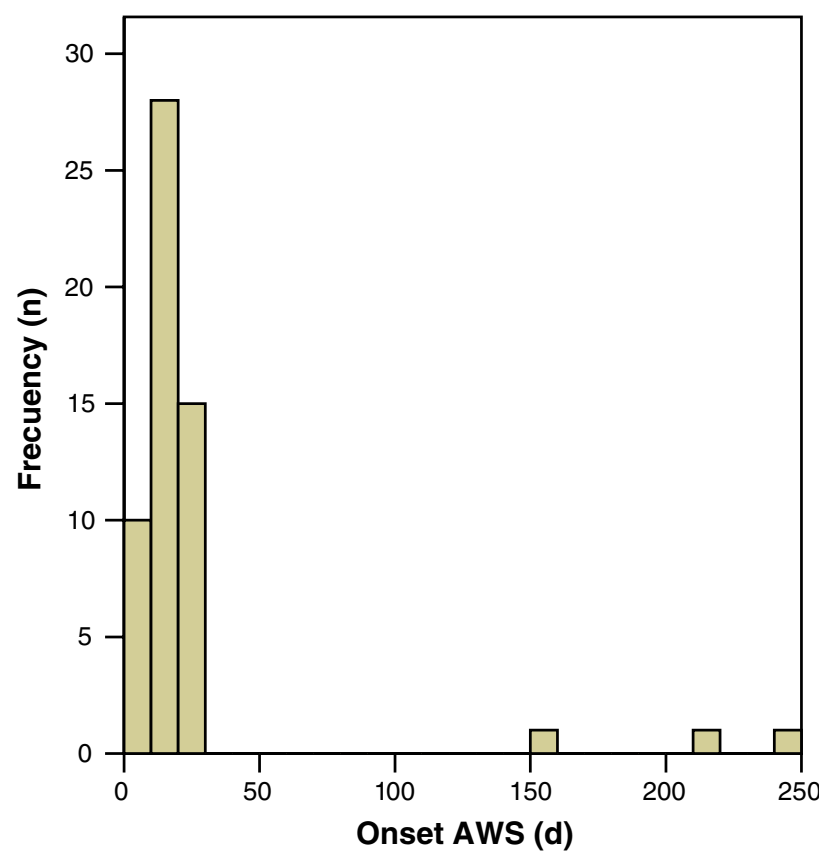

Fig. 3 Onset distribution of axillary web syndrome

previous studies indicate very different results. The incidence of AWS after ALND was only $6 \%$ in the study by Moskovitz et al. [15] and $72 \%$ in the study by Leidenius et al. [18]. The incidence we found in our study was $48.3 \%$, rather different than the incidence previously reported. The prospective setting of the present study with registration of the findings disturbing the patients (visible or palpable taut cords without restricting shoulder abduction, or without causing pain or SFT were not registered) is the most probable reason for the different incidence of AWS in the present study being close to those of Leidenius et al. [18].

Patients with AWS were slimmer $(\mathrm{BMI}=25.1$, SD 4.8) than those without AWS (BMI $=28.9$, SD 4.8). This finding is corroborated by Leidenius et al. [18] who suggest that the taut cords are less clearly visible or palpable under a thick subcutaneous layer. Nevertheless, in our study all those signs and symptoms disturbing the patients were taken into account for the diagnosis of AWS and still incidence was higher in slimmer patients. We think the most probable reason for this finding is mechanical: in women with more panniculus adiposus, lymph vessels would be cushioned by a bigger amount of fat, decreasing the characteristic signs and symptoms of vessel inflammation.

Also, the mean age of patients with AWS was lower (Mean age $=48.9$, SD 10.2) than those without AWS (Mean age $=58.1$, SD 10.9). This fact might be related to the BMI, because older people are more prone to gain weight $[29,30]$.

Axillary web syndrome developed mainly during the 2 week period after surgery, which matches previously reported findings [15, 18]. Although the follow-up was 12 months, we noted that three AWS appeared after this early post-operative 2 week period, after adjuvant therapy (chemotherapy and radiotherapy) (Fig. 2), and four patients with AWS in the early post-operative period suffered a recurrence of AWS in the period after adjuvant therapy 
(chemotherapy and radiotherapy). These finding could be related to the progressive obstruction of lymphatic vessels of the upper limb.

Six patients with AWS had a concomitant myofascial pain syndrome (MPS) of pronator teres muscle. The reason for the concomitance of pronator teres MPS and AWS is unknown, although we could hypothesize mechanical reasons related to protective splinting by the muscle, to avoid painful stretch of the taut cords of AWS at elbow level.

In addition it was found a significant association between the MPS and the AWS so that the AWS group subsequently presented more MPS than the group without AWS ( $\chi^{2}$ test, $P=0.010$ ). The MPS is defined as the signs and symptoms caused by myofascial trigger points (MTPs). An MTP can be defined as a hyperirritable nodule of spot tenderness in a palpable taut band of skeletal muscle. The spot is a site of exquisite tenderness to palpation, that refers pain to a distance, and that can cause distant motor and autonomic effects [31]. MTPs are thought to be localized muscle contractures occurring at dysfunctional motor endplate zones [31-34]. Reasons for the activation of MTPs include acute or chronic overload [31, 34] and leaving the muscle in a shortened position for a long period of time $[31,34]$. This association could be explained by the position maintained by the patient with AWS to avoid pain, in medial rotation and adduction of the shoulder and in flexion and pronation of the elbow, leading to the shortening of the muscles more often afflicted by MPS. As stated above, maintaining muscles in a shortened position is a well known MTPs activation factor [31, 34, 35].

At 3 months after surgery, resolution of AWS signs and symptoms was observed in almost all patients, as found by other authors [15, 18]. Regarding this issue, we usually apply a specific physical therapy protocol to treat the condition, but we don't yet have conclusive data regarding its effectiveness. Our physical therapy protocol includes manual lymph-drainage technique in axilla, and proximal ipsilateral arm, specific thumb manual lymph-drainage on the taut cords to make them gradually more flexible, in conjunction with progressive active and action-assisted shoulder exercises [20-22]. Although we got very good results (M. Torres, Unpublished data, 2008), compared to previous studies $[15,18]$, indicating that physical therapy shortens the natural course of axillary web syndrome in 6-8 weeks. This is consistent with the few case reports published on AWS physical therapy [20-22]. Future clinical trials are needed to support this therapeutic proposal.

\section{Conclusion}

This study has investigated the incidence of AWS after ALND. Axillary web syndrome is a significant cause of morbidity of axillary surgery, found in the early postoperative period and also in more advanced phases of the post-operative period. Research is needed to test therapies that can shorten the natural course of the condition.

Acknowledgments The authors would like to thank the staff and patients of Gynecology Service of Príncipe de Asturias Hospital from Alcalá de Henares (Madrid) and also thank the Physical Therapy Research Unit of the Physical Therapy Department, at Alcalà University in Madrid, (Spain).

Sources of support This clinical trial has been supported by Instituto de Salud Carlos III (Protocol PI071124), of Spanish Health Ministry. Physical Therapy Department from Alcalá University and Príncipe de Asturias University Hospital provided the facilities to carry out the study.

\section{References}

1. Donegan W (1992) Prognostic factors: stage and receptor status in breast cancer. Cancer 70:1755-1764. doi:10.1002/1097-0142 (19920915)70:4+<1755::AID-CNCR2820701617>3.0.CO;2-G

2. Bergkvist L, Boniface J, Jönsson P, Ingvar C, Liljegren G, Frisell J (2008) Axillary recurrence rate after negative sentinel node biopsy in breast cancer: three-year follow-up of the Swedish multicenter cohort Study. Ann Surg 247(1):150-156

3. Sanjuàn A, Vidal-Sicart $S$, Zanón G, Pahisa J, Velasco $M$, Fernández P, Santamaría G, Farrús B, Muñoz M, Albanell J et al (2005) Clinical axillary recurrence after sentinel node biopsy in breast cancer: a follow-up study of 220 patients. Eur J Nucl Med Mol Imaging 32:932-936. doi:10.1007/s00259-005-1763-6

4. Lin P, Allison D, Wainstock J (1993) Impact of axillary node dissection on therapy of breast cancer patients. J Clin Oncol 11:1536-1544

5. Carter C, Allen C, Henson D (1989) Relation of tumor size, lymph node status, and survival in 24.740 breast cancer cases. Cancer 63:181-187. doi:10.1002/1097-0142(19890101)63:1<181:: AID-CNCR2820630129>3.0.CO;2-H

6. Douay N, Akerman G, Clément D, Malartic C, Morel O, Barranger E (2008) Seroma after axillary lymph node dissection in breast cancer. Gynecol Obstet Fertil 36(2):130-135. doi:10.1016/ j.gyobfe.2007.07.040

7. Francis W, Abghari P, Du W, Rymal C, Suna M, Kosir M (2006) Improving surgical outcomes: standardizing the reporting of incidence and severity of acute lymphedema after sentinel lymph node biopsy and axillary lymph node dissection. Am J Surg 192:636-639. doi:10.1016/j.amjsurg.2006.08.018

8. Kitamura Y, Ohno Y, Kasahara S, Murata K, Sugiyama H, Oshima A, Tsukuma H, Ajiki W, Hasegawa T (2005) Statistical estimation of the number of breast cancer patients with disabilities resulting from surgery. Breast Cancer 12(2):130-134. doi:10.2325/jbcs. 12.130

9. Madsen A, Haugaard K, Soerensen J, Bokmand S, Friis E, Holtveg H, Garne J, Horby J, Christiansen P (2007) Arm morbidity following sentinel lymph node biopsy or axillary lymph node dissection: a study from the danish breast cancer cooperative. Breast 10:291-401

10. Nesvold I, Dahl A, Løkkevik E, Marit Mengshoel A, Fosså S (2008) Arm and shoulder morbidity in breast cancer patients after breast-conserving therapy versus mastectomy. Acta Oncol 47(5):835-842. doi:10.1080/02841860801961257 
11. Steegers M, Wolters B, Evers A, Strobbe L, Wilder-Smith O (2008) Effect of axillary lymph node dissection on prevalence and intensity of chronic and phantom pain after breast cancer surgery. J Pain 1(6):1-10

12. Unalp H, Onal M (2007) Analysis of risk factors affecting the development of seromas following breast cancer surgeries: seromas following breast cancer surgeries. Breast J 13(6):588-592. doi:10.1111/j.1524-4741.2007.00509.x

13. Vitug A, Newman L (2007) Complications in breast surgery. Surg Clin North Am 87(2):431-451. doi:10.1016/j.suc.2007.01.005

14. Wilke L, McCall L, Posther K (2006) Surgical complications associated with sentinel lymph node biopsy: results from a prospective international cooperative group trial. Ann Surg Oncol 13:491-500. doi:10.1245/ASO.2006.05.013

15. Moskovitz A, Anderson B, Yeung R, Byrd D, Lawton T, Moe R (2001) Axillary web syndrome after axillary dissection. Am J Surg 181:434-439. doi:10.1016/S0002-9610(01)00602-X

16. Ferrandez J, Serin D (1996) Rééducation et cancer de sein, 1st edn. Masson, Paris

17. Ferrandez J, Serin D (2006) Rééducation et cancer de sein, 2nd edn. Elsevier Masson S.A.S, Paris

18. Leidenius M, Leppanen E, Krogerus L, von-Smitten K (2003) Motion restriction and axillary web syndrome after sentinel node biopsy and axillary clearance in breast cancer. Am J Surg 185(2):127-130. doi:10.1016/S0002-9610(02)01214-X

19. Reedijk M, Boerner S, Ghazarian D, McCready D (2006) A case of axillary web syndrome with subcutaneous nodules following axillary surgery. Breast 15(3):411-413. doi:10.1016/j.breast. 2005.09.005

20. Ferrandez JC, Doyer M, Serin D, De Rauglaudre G (2007) Thromboses lymphatiques superficielles. In: Petiot S, Hérisson C, Pélissier J (eds) Cancer du sein traité et médecine de rééducation. Elsevier-Masson, Paris, pp 119-128

21. Torres M (2006) Caso clínico 13: Dolor en la cara medial del brazo. In: Torres M, Salvat I (eds) Guía de Masoterapia para Fisioterapeutas. Médica Panamericana, Madrid, pp 337-342

22. Torres M, Cerezo E (2009) Actuación fisioterapéutica en la trombosis linfática superficial tras cirugía mamaria con linfadenectomía. A propósito de un caso. Cuest fisioter 38(1):34-38

23. De Kroon KE, Roumen RM (2004) Diagnostic image (184). Two women with painful bands after axillary lymph node removal.
Lymphatic thrombosis and fibrosis. Ned Tijdschr Geneeskd $15: 729$

24. Ohnhaus E, Adler R (1975) Methodological problems in the measurement of pain a comparison between the verbal rating scale and the visual analogue scale. Pain 1:379-384. doi:10.1016/ 0304-3959(75)90075-5

25. Jensen M, Karoly P, O'Riordan E (1989) The subjective experience of acute pain: an assessment of the utility of 10 indices. Clin J Pain 5:153-159. doi:10.1097/00002508-198906000-00005

26. SPSS for Windows (2007) (12.0 version). In: SPSS Inc., Chicago, USA

27. Domenech J, Sesma R, Bonillo A, Granero R (2007) Confidence intervals for proportions (exacts and asymptotics). In: Barcelona. Available from: www.metodo.uab.es/macros.htm

28. Domenech JM, Bonillo A, Granero R (2005) Sample Size: estimation of population proportion. In: Barcelona. Available from: www.metodo.uab.es/macros.htm

29. Hedley AA, Ogden CL, Johnson CL, Carroll MD, Curtin LR, Flegal KM (2004) Prevalence of overweight and obesity among US children, adolescents, and adults, 1999-2002. JAMA 291:2847-2850. doi:10.1001/jama.291.23.2847

30. Mokdad AH, Serdula MK, Dietz WH, Bowman BA, Marks JS, Koplan JP (1999) The spread of the obesity epidemic in the United States, 1991-1998. JAMA 282:1519-1522. doi:10.1001/ jama.282.16.1519

31. Simons DG (2004) Review of enigmatic MTrPs as a common cause of enigmatic musculoskeletal pain and dysfunction. J Electromyogr Kinesiol 14(1):95-107. doi:10.1016/j.jelekin.2003. 09.018

32. Simons D, Travell J, Simons L (2002) Dolor y disfunción miofascial. El manual de los puntos gatillo. Mitad superior del cuerpo, 2nd edn. Médica Panamericana, Madrid

33. Lewit K, Olsanska S (2004) Clinical importance of active scars: abnormal scars as a cause of myofascial pain. J Manipulative Physiol Ther 27(6):399-402. doi:10.1016/j.jmpt.2004.05.004

34. Simons DG, Travell JG, Simons LS (1999) Myofascial pain and dysfunction. The trigger point manual. Upper half of body, vol 1, 2nd edn. Williams \& Wilkins, Baltimore

35. Gerwin RD, Dommerholt J, Shah JP (2004) An expansion of Simons integrated hypothesis of trigger point formation. Curr Pain Headache Rep 8:468-475. doi:10.1007/s11916-004-0069-x 